in press, International J ournal of Child-Computer Interaction - accepted for publication 31 st July 2019 - Author version

\title{
Prosocial games for inclusion: interaction patterns and game outcomes for elementary-aged children
}

\author{
Sarah Parsons ${ }^{a^{*},}$ Efstathia Karakosta ${ }^{a}$, Michael Boniface ${ }^{b}$, Simon Crowle $^{b}$ \\ * corresponding author \\ a Southampton Education School, University of Southampton, Highfield, Southampton, SO17 \\ 1BJ , U.K. \\ s.j.parsons@soton.ac.uk; e.karakosta@soton.ac.uk \\ b IT Innovation Centre, Electronics and Computer Science, University of Southampton, \\ Gamma House, Enterprise Road, Southampton SO16 7NS, U.K. \\ mjb@it-innovation.soton.ac.uk; simoncrowle@yahoo.com
}

\begin{abstract}
There is good evidence that children's prosocial skills are positively associated with health, well-being, and academic outcomes. Games-based approaches have demonstrated strong potential for teaching prosocial skills in both digital and non-digital formats. However, much of this research focuses on middle-childhood and adolescence and is based on self-reports from teachers, children, and parents. This paper reports on the pilot evaluation of a digital co-operative game (The Chase), which is based on a 'shared goal' interaction pattern such that children have to co-operate in order to be successful in the game. 49 children from Italy and 22 children from the UK, aged 7-10 years participated, playing the game twice in small groups during the course of a day. Children's moves during gameplay were assessed using logging data, and their interactions with each other represented using a graphical social network analysis. Usability feedback was also obtained from some children and pedagogical possibilities explored with teachers. Findings show that even within a very short period children shifted towards a more co-operative mode of play. The social network analysis revealed the dynamics of these interactions while playing the game. Children enjoyed the game and were highly motivated by it, and teachers were very enthusiastic about the possibilities for embedding the game in their curriculum. These findings provide an encouraging basis for extending the range of digital prosocial games available for elementary-aged children and evaluating these as pedagogical tools for facilitating prosocial behaviours.
\end{abstract}

Keywords: cooperative/ collaborative learning; elementary education; evaluation methodologies; pedagogical issues; teaching/ learning strategies 
Declarations of interest: none

\section{Highlights}

- A novel co-operative prosocial digital game for elementary children is evaluated

- Children were more prosocial in the game following only short sessions of game-play

- Innovative graphical network analysis illustrates children's dynamic interactions

- The acceptance of the game was high amongst teachers and children 


\section{Introduction}

The importance of children's development of prosocial competence for health, well-being, and good academic outcomes is well established [1, 2]. Prosocial skills are defined in various ways by different authors but at their core represent behavioural and cognitive skills that underpin voluntary, positive behaviours towards others such as helping, co-operating, turntaking, empathising, and trusting [3]. There is good evidence for the power of prosociality on longer-term social and academic outcomes (e.g.[4]). Conversely, poor prosociality, as measured by low peer acceptance, predicts declines in academic performance over time [5]. There is increasing recognition that facilitating the development of prosocial skills should, therefore, be a universal and inclusive strategy that encompasses all children before problems arise [1, 2], which has been shown to promote resilience and protective factors that mitigate against poor social and academic outcomes [6, 7].

There is good evidence that games-based principles can be highly motivating and effective for supporting prosocial outcomes for children [e.g. 8, 9, 10, 11]. The role of digital games in this context has also been widely investigated with research demonstrating positive benefits for learning in general for digital games when compared to non-game-based teaching [12]. Systematic reviews of the field, focusing on participants aged 14 years and older [13, 14] describe a range of benefits and outcomes of playing digital games including knowledge and skills acquisition, behaviour change, and collaboration (see also [15]). More widely, Stewart et al., [16] argue that digital games can play a strong role in supporting social and educational inclusion. Indeed, the potential of digital games for supporting inclusive pedagogy is emphasised by Harrington and O'Connell [17, pp.657-8]:

Video games do not depend exclusively on formal literacy and numeracy to teach skills and convey social messages. Therefore video games with prosocial content could become a vital pedagogical tool in the educational provision for youth from disadvantaged communities. 
In alignment with this statement, there is growing awareness of the value of playing prosocial video games for supporting prosocial behaviours, thereby providing a strong counterpoint to the numerous reports linking the playing of video games with violence or aggression [18, 19]. For example, Harrington and O'Connell [17] found a strong and significant positive association between prosocial video game use and prosocial behaviours and cognition in a self-report study of 538 students aged 9-15 years in the Republic of Ireland. Other large-scale correlational studies in Singapore and J apan with students aged 10-13 years show similar findings [20].

In a more direct test of the relationship between playing prosocial digital games and improving or displaying prosocial behaviours, Gentile et al., [20] reported an experimental study of 161 college students aged 19 years on average. Students were randomly allocated to a prosocial, violent, or neutral game condition and were asked to play the game for 20 minutes. Following gameplay, students were asked to give a peer a puzzle task which could be easy or hard; they were told that their peer would be rewarded with vouchers if $\mathrm{s} / \mathrm{he}$ successfully completed a number of puzzles. Findings clearly demonstrated that students who played the prosocial game were significantly more likely to give their peer easy puzzles to complete, while those who played the violent game gave their peer more difficult puzzles. After only 20 minutes of use this study provides a strong indication of the power of prosocial gameplay on directly influencing proximal positive behaviours.

Nevertheless, much of the research in this area that explores the association between prosocial digital game play and prosocial behaviours is based on individual self-reports of children, teachers, and parents e.g. [21, 22]. While these studies provide valuable insights, and the findings of studies are generally consistent, they are limited by this methodological weakness as it is difficult to rule out social desirability biases [23]. Studies reporting direct investigations into behaviours and learning in response to playing video games have been conducted, usually via quasi-experimental designs e.g. [14, 12, 20]. However, these tend to 
focus on older children, adolescents, and young adults playing off-the-shelf games [3, 19], rather than younger children who are likely to benefit the most from earlier intervention [24]. These studies also tend to rely on individual ratings or behaviours and correlations between measures of these, rather than looking directly at behavioural interactions between children. While individual ratings and behaviours clearly have value, analysis of real time interactions between children would provide different insights into how children's prosocial understanding and games exposure translate into practice. There are many examples of digital games or software being developed to target the specific needs of particular learners e.g. for social and communication difficulties [25]; and for reading and literacy [26]. However, such approaches do not provide evidence for the wider use and benefits of prosocial games in a socially and educationally inclusive context.

Thus, there are very few examples, to the best of our knowledge, which take an inclusive approach and directly explore the responses of elementary-aged children, irrespective of special or specific educational needs, to prosocial gameplay in schools. In agreement with others [16] we recognise that gaps remain in the evidence base with regard to prosocial gaming and that more research needs to be done to examine behaviours and responding in more detail [27]. As Passmore and Holder [19, p.142] note: "This [gap in the evidence base] is not surprising, given that this is a relatively new domain of research".

\subsection{The contribution of the current study}

The present study therefore aims to contribute to this emergent evidence base in a number of ways. First, a bespoke co-operative prosocial game - The Chase - is outlined, which was designed specifically for elementary school children aged 7-10 years to be played in small groups in class (2-4 players). The Chase was designed using a particular conceptual approach (see section 2.2) which is summarised here to contextualise the study. Second, logging data from classroom trials, in the UK and Italy, are presented to show how children responded to the game and to assess whether prosocial behaviours and outcomes were supported. Third, patterns of interactions between children are presented using a novel 
graphical social network analysis. Finally, usability feedback from children and teachers is summarised, as well as brief comments from teachers regarding the potential of The Chase for supporting children's prosocial learning in schools. Specifically, the research questions addressed in this study were:

1. Does The Chase encourage children to respond prosocially within the game?

2. What kinds of social interaction patterns around the game are revealed between groups of children playing The Chase?

3. To what extent do teachers and children find The Chase easy, enjoyable and acceptable to use in the classroom?

\section{Methodology}

\subsection{Conceptual framework for designing and evaluating The Chase}

Crook [28] recognised early on the culturally, and socially, embedded nature of classroombased computer use such that researchers should pay as much attention to activities taking place around the computer as within computer-based tasks. Abbott [29] extended these ideas to define e-inclusion practices which emphasize '...the interaction between digital tools, contexts and people, and focuses attention on the activity of the use of digital technologies' [29, p.6; our emphasis]. Thus, our approach to evaluation of the activity of the use of the digital game included: (1) the direct responses of children within a prosocial game, (2) their interactions with each other while using the game, (3) their feedback and perspectives on the game, and (4) the views of teachers regarding the usefulness and potential of the game.

The framework for the design and development of The Chase aligns with the approach to evaluation by emphasising the socially and culturally embedded nature of interactions within and around technology, and the positioning of technologies as powerful mediational tools through which children's interactions and meaning-making are supported. This strongly Vygotskian, social-constructivist approach to learning and pedagogy is, of course, not new 
and reflects the powerful affordances of digital games as mediational tools that are intrinsically motivating and rewarding $[15,16]$. The details of the game design are discussed in more detail elsewhere [30] but in essence The Chase uses a skills-based approach, based on [31] and [32] to define prosocial behaviours and translate these into actions supported or enabled through the game. Specifically, The Chase follows a co-operative 'shared goal' game design [33] which is a pattern of play that requires players to cooperate in order to advance and win the game. There is good evidence that cooperative gameplay positively supports prosocial behaviours [19]. The game can only be played in pairs and small groups and children have to work with each other to complete or win the game.

\subsection{Description of The Chase prosocial game}

The skills that are required, and practised, through The Chase are 'skills for collaboration', specifically: cooperation, taking turns, asking for help, and helping others. The game is based on a simple board game (Ludo-type) layout where up to four players take turns to move their teams' pieces along a series of steps and away from the 'Giggle monster' who chases the players. Each player starts the game with 25 balloons which they must try to retain through the game. The aim of the game is that, as a team, the players must try to keep 60 or more balloons between them in order to escape in a hot air balloon at the end of the path. On each turn, 0, 1 or 2 moves are randomly assigned to a player (or the Giggle monster) following the spin of a virtual counter. If the monster lands on one or more players, then five balloons are sacrificed for each. However, the players can avoid this by cooperating to move each other's pieces immediately in danger of being caught by the monster (this costs 1 balloon per move for the player helping others). Thus, children can choose to work together prosocially to win the game and escape the monster (which comes at a cost to their own balloon stash), or they can decide to act individually to retain their own balloons but risk the overall total. Therefore, players need to negotiate and discuss their strategy to decide what's best for the group. 
The Chase can be played on PCs or tablets that are connected wirelessly to the game server. Each child has their own PC or tablet through which they interact with the game, and around which, with each other. The game server automatically logs the interactions made within the game including the timing of the game and the kinds of moves that the children make. More information about the technical aspects and design of the game can be found in [34]. Figure 1 shows a screenshot of The Chase game.

$$
\text { *** Insert Fig.1 about here*** }
$$

\subsection{Participants}

Two groups of children took part. The first group, from two elementary schools in Italy, included 49 children: 11 girls and 13 boys from the first school, and 7 girls and 18 boys from the second school, aged 7-10 years (hereinafter, the 'Verona group'). The second group included children from one mainstream elementary school and one specialist school in the UK. The sample consisted of 17 children ( 7 girls and 10 boys) from the elementary school and 5 children ( 1 girl and 4 boys) from the specialist school (hereinafter, the 'Southampton group'). Children from these two countries were included because of the resources and expertise within the project consortium. Given that all schooling in Italy takes place in inclusive classrooms, it can be assumed that some children with additional learning needs were included in the Verona group, although this information was not gathered explicitly (verbal communication with the teacher suggested that one child in the group had special educational needs). In the Southampton group, five of the children from the mainstream school had English as an additional language, and four were identified as having special educational needs. In the specialist school, all five children had specific additional learning needs. From the Southampton group, two teachers also took part: one female teacher from the mainstream school who taught children aged 8-9 years, and one female teacher from the specialist school who taught children aged 8-11 years.

\subsection{Procedure}


In Italy and the UK, the implementation of the game took part in classroom settings as part of the normal school timetable with the children's teacher present at all times, alongside a researcher from the project. Children played the game twice in groups of four (with a few exceptions, see Table 1). In Italy children played The Chase while sat around a table via Android tablets provided by the research team. In the UK, children played the game via PCs in their classroom or ICT Suite, with the PCs being lined up in a row so that children were sat next to each other. Table 1 summarises the total number of play sessions and groups involved from each school. Teachers decided on the composition of the groups.

\section{*** Insert Table 1 about here***}

For all groups, the researcher introduced the game concept to the children and then they played the game. Following game play, there was a 5-10 minute discussion about whether children enjoyed playing the game, how they felt about the collaboration with the other players and, based on the outcome of the game, whether they were pleased or had any thoughts for achieving a better outcome. Then children were asked to play the game one more time in the same groups. The duration of each game session ranged from 3-10 minutes (the game was much shorter for children who worked only in pairs). In Italy, after all groups had played the game there was a 10-minute class debrief and discussion. In the UK, after the second game, the children completed a feedback form providing information about their experience from playing the game [see section 2.4.2(a)]. The class teachers in the mainstream and specialist school also completed a usability questionnaire and participated in a short interview [see sections 2.4.2(b) \&(c)].

\subsubsection{Data capture}

For the Verona groups the sessions were not videotaped but children's moves within the game were automatically logged by the game server and qualitative feedback from children obtained (the latter is reported in [34]). In the Southampton groups, children's moves were also automatically logged and all sessions videotaped. The Chase's game platform automatically captures children's button presses (the 'moves' in the game) in a way that 
identifies the data from a specific PC/ tablet during a specific game and specific group/ pair session. Whilst maintaining children's anonymity (each child was randomly assigned a 'code name' for login e.g. the name of an animal) their moves when playing the game were logged and classified as selfish, neutral or cooperative, based on whether children helped only themselves (selfish), did not threaten or facilitate the moves of any of the other players (neutral), or helped another player (cooperative).

\subsubsection{Additional UK specific measures}

\subsection{2 (a) Children's Feedback Form}

After each group or pair of children completed the second session, a feedback form was provided in order to collect information about their experiences and views of playing the game. This feedback form consisted of three sections and took 5-7 minutes to complete. The first section requested some basic demographic data, such as gender and age and the rest was based on Obrist et al.'s [35] questionnaire, which examined children's fun levels of the game and willingness to play the game again. The second section was based on the Scenario Experience Feedback Questionnaire (SEFQ) [36], which explores children's enjoyment, understanding, ease of use, and other usability issues e.g. 'did you enjoy the game?', 'did you feel you could control the game?' This section contained 12 items, rated on a 5-point likert scale from 'not at all' to 'very much'. The third section included three open-ended questions asked children's views about the game: 'what did you like / not like about the game', and 'what did you think the purpose of the game was?'

\subsection{2 (b) Teachers' Usability Questionnaire}

This questionnaire was based on the System Usability Scale (SUS) [37] which examines three usability criteria: effectiveness, efficiency and satisfaction. It comprises 16 statements scored on a 5-point likert scale of strength of agreement ranged from 'Not at all' to 'Very much'. Teachers also supplied some introductory information such as their role in the school and the year group they teach. Its completion took approximately 5 minutes. 


\subsection{2 (c) Teacher Interviews}

Semi-structured interviews with the two UK teachers were held at the end of the study in order to explore their views about the games and possible ways of integrating prosocial skills within the mainstream or specialist class learning context. The interviews took place in the schools at a time convenient to the teachers' timetable, lasted approximately 16 minutes, and were audio recorded.

\subsubsection{Ethics}

Informed consent procedures in Italy and the UK aligned with the norms and expectations within each country. In Italy, children and their head teacher in loco parentis received a Participant Information Sheet. Consent from parents was covered by the consent provided at the beginning of the year by the participants' legal guardians to the school. Additionally, signed letters from the schools' head teachers were obtained as well as signed consent forms from teachers of the classrooms where children participated. An Italian project collaborator, remained on hand to deal with any questions or concerns that either staff or the children might have. This part of the study was reviewed and approved by the University of Southampton's Faculty of Physical Sciences and Engineering Ethics Committee (Ref \# 19796).

In the UK, the schools who agreed to take part in the study received information sheets giving details about the project and consent forms for parents and teachers. Children were also asked for their agreement to take part using a simplified assent form. Apart from the voluntary nature of the teachers', parents' and children's' participation and their right to withdraw at any time during the study, it was also made clear to them that the game sessions would video record what children say to each other and the moves they make during the game. Parents could decide whether or not images or clips of the game sessions may be used in project dissemination (17 out of 22 parents agreed to this). Ethical review and approval for this part of the study was provided by the Faculty of Social, Human, and Mathematical Sciences Ethics Committee of the University of Southampton (Ref \#24065). 


\section{Results and Discussion}

As noted in section 2.1, there are four main sections of data that illustrate the activity of use of The Chase and these are reported in turn below. Section 3.1 includes data from the Verona and Southampton groups, while sections 3.2-3.4 include data from the Southampton group only.

\subsection{The direct responses of children within The Chase prosocial game}

The outcome of the game was logged as a 'win', a loss', or 'unfinished'. The game was won when all players reached the end of the path and had retained a sufficient number of balloons to fly off together in the hot air balloon. Overall, the outcome of the games in Italy was 11 winning games ( six in session 1, five in session 2), eight losing games (five in session 1 , three in session 2), and three unfinished games (one in session 1, two in session 2). In the UK, there were seven winning (three in session 1, four in session 2), and seven losing games in total (four in session 1, three in session 2).

Children's button presses (moves) within the game were automatically logged and classified as selfish, neutral or cooperative (see Table 2). The classification considers the threat state of the game on each turn. This state consists of the threats to the active player and the other players. If the active player is under threat themselves then all moves are considered neutral as saving themselves from the giggle monster, even when others are also under threat, is considered neither selfish nor cooperative behaviour. If, however, the active player is not under threat but other players are then the player has a choice to either move themselves or another player. If they move themselves under this state this is considered a selfish move, whereas if they move another then they are helping the team and acting cooperatively. Neutral moves make up six out of the eight possible response options and so a dominance of neutral moves would be expected when playing the game. 
*** Insert Table 2 about here***

In both the UK and Italy a similar pattern of results was found: the majority of moves (75\%83\%) were neutral, as anticipated. Therefore, the comparison of real interest is between cooperative and selfish moves where players could choose to protect themselves at the expense of another, or could choose to sacrifice some of their own balloons in order to protect the overall total of balloons. Across the groups, children made more co-operative moves and fewer selfish moves in the second session compared to the first (see Figures 2 and 3).

*** Add Figs 2 and 3 about here ***

Comparing the number of selfish and co-operative moves between sessions 1 and 2 across all children (Verona and Southampton combined) there was a significant change between sessions 1 and 2: $\chi^{2}(1)=9.20$ (corrected), $p=0.002$. Taking each group separately, there was a significant change in the Verona group $\chi^{2}(1)=5.47$ (corrected), $p=0.019$; and a marginal effect in the Southampton group $\chi^{2}(1)=3.75$ (corrected), $p=0.053$. This shows that even after a very short period of prosocial gameplay, children significantly shifted their responses away from selfish moves and towards more co-operative moves, even though the overall outcomes of the games (win or lose) did not change very much between the sessions. The marginal effect in the Southampton group is likely due to the smaller sample size, but the trend towards more co-operative moves is clear. With reference to our first research question: 'Does The Chase encourage children to respond prosocially within the game?', the answer is 'yes'.

This finding is, at least partially, in alignment with Gentile et al., [20] who demonstrated a rapid prosocial effect on behaviours following a short period of digital game play. Their study was with college students whereas ours was with much young children, and theirs considered prosocial behaviour after playing digital games, whereas ours considered prosocial behaviour during gameplay. The next steps for us will be to demonstrate whether the within-game shift in behaviour can be demonstrated with other prosocial games too, and whether prosocial behaviours outside of the game context can also be positively influenced 
for elementary-aged children. These steps are planned for the project of which this pilot study was a part. Overall, this pilot study provides an encouraging basis for taking those next steps.

\subsection{Children's interactions with each other while using The Chase prosocial game}

The Chase sessions for the Southampton group were video recorded in order to examine children's dynamic interactions with each other while playing the game. Social Network Analysis (SNA) was used as it helps to identify the relationship patterns between people who constitute members of a social network [38]. Bokhove [39] used a novel graphical social network analysis for mapping real-time classroom interactions between children and teachers. However, such an approach has not been applied, to the best of our knowledge, to dynamic behavioural interactions between children recorded in real time to examine who was actually interacting with whom during prosocial digital game-play. Thus, we present an innovative analytical approach to demonstrating patterns of behaviour in this context.

The video footage from 14 sessions ( 4 groups $\mathrm{x} 2$ sessions +3 pairs $\mathrm{x} 2$ sessions) was analysed via Gephi 0.9.1 software (Gephi Consortium, 2016), which provides an interactive visualization and exploration platform for all kinds of networks and complex systems, dynamic and hierarchical graphs' (Gephi Consortium, 2016). Only the data from the four groups from the mainstream school (eight sessions in total) are included below, since the interactions between pairs at the special school provide little scope for examining changes between the first and second sessions. This is because the weighting and direction of arrows between two children is much more limited in terms of what can be visually represented than between more than two children.

The analysis per group provides a more nuanced overview of how frequently children were interacting with each other during gameplay, and specifically enabled us to identify the children who initiated or responded to interactions more often compared to their coplayer(s). The child who initiated the interaction (i.e. sender) was indicated as a source node 
and the child who was the receiver constituted the target node. In cases where the children talked to themselves while playing the game (e.g. comment on the number of moves they had to make after spinning the wheel etc.), they were considered both as source and target nodes.

An inter-rater reliability check was conducted on the video data. An independent rater fully coded three (from eight) randomly selected group sessions focusing on initiations and responses. This independent coder was not involved in the study, nor part of the research team, and did not meet any of the children. Overall Pearson's r revealed a strong and significant positive correlation between the main coder (who coded all of the data) and the independent coder, across the three videos $(r=.897$ and $\mathrm{p}<.001)$, indicating very close agreement.

Figure 4 shows the total number of interactions per child (combining the initiation and response data), and Figure 5 the average number of interactions per group, within each session. These graphs begin to illustrate the substantial heterogeneity between the groups, and between individual children, in terms of how they interacted with each other during the game. Specifically, Groups 1 (children 1-4) and 4 (children 13-17) tended to interact with each other less (in the case of Group 1, much less) in the second session, whereas the opposite pattern was true for Groups 2 (children 5-8) and 3 (children 9-12) who interacted with each other more on the second session. It is also clear that Group 1 interacted with each other much more overall than any of the other three groups. Given this heterogeneity across the groups it is not surprising that there were no statistically significant changes according to Wilcoxon Signed Rank Tests between sessions 1 and 2 on these measures.

***Insert Figures 4 and 5 about here***

The graphical patterns of interaction, as visualised through the Gephi software using the weighted-in and - out data for each child (i.e. response and initiation data respectively, Figure 6) add a further level of detail about the behaviours within each group. Visual inspection of the graphs shows that the overall dynamics changed for each of the groups between the first and second session. Taking Group 1 session 1 as an example (top left on 
Figure 6), there is a lot of interaction during this session, especially when compared to the other groups. The interactions are mostly between child 1 and child 4, 2 and 3, and child 3 and 4 , while there was limited interaction between child 1 and 2 . This is shown visually by the thicker arrows in-between these children, while the arrows also show the direction of these interactions. For example, child 2 (source node) initiated more often to child 3 (target node). Overall though, there is a fairly balanced contribution from the four children, as shown by the crossed pattern of interactions as well as the data in Figure 4 . This balance was largely maintained into the second session, although interactions between child 2 and 3 were more dominant / frequent relative to the other children. Compare the interaction patterns of Group 1 with those of Group 4 (Figure 6, bottom row). Here, a very different pattern can be seen with interactions between child 1, 2, and 5 dominating in session 1 and then a shift towards more balanced contributions from children in session 2. Although the average number of interactions fell very slightly for Group 4 between the first and second session, Figures 5 and 6 show that there was more reciprocal and shared interactions between the group members compared to the first session.

***Insert Figure 6 about here***

The second research question asked: What kinds of social interaction patterns around the game are revealed between groups of children playing The Chase?' Bokhove [39, p.19] describes the visual presentation of data via a graphical network analysis as instantly appealing' because there is an immediacy about what is conveyed to the reader. In this case, the network analysis provides an indication of the overall balance of interactions across the group and between individual members. It is clear, for example, in the second session for Group 2 that child 4 has become more isolated from the interactions between the group, and in Group 4, child 3 remains fairly isolated from the interactions during both sessions. We did not transcribe or analyse the verbal and non-verbal interactions between children and so cannot provide systematic insights into exactly what was being said or conveyed, however it was clear from the video footage that some children were more dominant, while others were 
more reluctant to join in. Indeed, in Group 4 one child was clear in her feedback after the session that her main focus was avoiding the giggle monster and so this could in part explain a style of interaction that appears more withdrawn.

This dynamic network analysis is, nevertheless, potentially very useful for two main reasons. First, it can reveal reciprocity (or not) between children in the group such that it becomes possible to identify who may be at risk of exclusion, and second, it helps to identify the specific nature of interactions that may need to be supported for individual children e.g. to increase or decrease their initiations or responses. The use of such an analysis would be helpful from a research perspective for showing whether there are changes over time in the ways that children relate to each other, and how this may impact on their social and academic outcomes [e.g. 40].

To be useful for practitioners, however, technology would need to be able to provide realtime indicators of interactions very swiftly following gameplay. In this context, the use of sensors for movement, speech, or facial expressions (for example) could be implemented within prosocial games to support the provision of helpful feedback for teachers and children. Numerous options for sensor-based feedback have been reported in the literature, demonstrating some promising potential for supporting learning [e.g. 41, 42], although there are many gaps with regard to how and when information can be most effectively used for formative feedback [43]. This is a logical and fruitful avenue for future research and something that the project is actively pursuing by examining sensor-based feedback for emotional affect of interaction and reciprocity of responding.

\subsection{Children's feedback and perspectives on The Chase prosocial game}

22 feedback forms were received from children from the Southampton group ( 14 boys, 8 girls). 21 out of the 22 children said that the game was fun, and all 22 said they would like to play the game again. The majority thought that The Chase was 'Great' (n=18), Fun' (n=18) and 'Exciting' ( $\mathrm{n}=15)$, while none of them thought that it was 'Ugly', 'Bad' or 'Boring'. Six children found the game 'Confusing' and 'Difficult', while seven children said it was 
'Surprising'. Responses to the SEFQ section of the feedback form are summarised in Table 3 and confirm children's overall positive views. The majority felt that the game was fun and easy to play despite not always succeeding in winning, and the game being a bit slow to respond. Encouragingly, the strongest response indicated that 20 children 'very much' liked playing the game as a group. Children's open comments about the game also showed that they liked it, especially being able to work together e.g. 'We could all work together because one person wouldn't be successful.' Four children thought that the game was about team work and safety e.g. 'To work as a team - to finish as a team'; four were more literal and described the game e.g. Not to get trapped by the giggle monster and lose the balloons'; two thought the game was to help with maths, and two thought it was about having fun.

$$
\text { ***Insert Table } 3 \text { about here }{ }^{* * *}
$$

The critique of educational games being 'chocolate covered broccoli' is very widespread and much discussed in the games design literature [e.g. 44], the idea being that many educational games fail to be motivating and engaging because the learning and the fun in the game are unconnected. This was clearly not the case here as the majority of children really enjoyed playing The Chase, and many identified the core element of the game as 'working together as a team' while also finding the game fun. This suggests that there was a good balance between the obvious fun of the game and the (more implicit) learning about the value of playing cooperatively with peers.

\subsection{Teacher feedback regarding the usefulness and potential of the game}

The two teachers' responses on the System Usability Scale (SUS) showed that they were very positive about the game, suggesting that most people would learn to use this game very quickly, children in their class would find the game interesting, and that the game's concept about collaboration, taking turns, asking for help and helping others is important for children. In addition, they both replied that a game such as The Chase would be useful as a basis for discussions in their classroom concerning collaboration, taking turns, asking for help and helping others, and that the game would be useful for developing skills for 
collaboration between children. One teacher also suggested that mixing it in with maths could also provide a useful and interesting option.

Findings from the interviews with teachers confirmed and extended these positive views. They felt that children understood they had a common goal when playing the game and needed to work together;

Children can help each other, play together and can't sabotage each other as part of the game. There was no sort of antagonistic aspect to it.

Both teachers said that children not only enjoyed playing the game ('overwhelmingly positive'), but children also asked to play the game again after the study's completion. The specialist school teacher highlighted the importance of collaboration especially for the children who have some difficulties with this:

Children do have to collaborate in order to win the game. It's not all about themselves, it's a joint effort so they have to work together and this is brilliant especially for children that struggle with that. Also it's fun, interactive and children likeit.

The acceptance of games-based learning by teachers is critical for adopting games in classrooms [e.g. 45]. Thus, the positive appraisal of games by teachers in terms of perceived usefulness and ease of use is a vital step in facilitating uptake of games within teaching [46]. Crucially, these teachers could see how much children enjoyed playing the game with each other, as well as how they behaved during gameplay. Initially, one of the teachers was sceptical because the graphics of the game are not sophisticated and she wondered whether the game would hold the children's attention. However, once played, she could really see the benefits for the class and the enthusiasm of the children. Of course, there were only two teachers involved in this study and these were likely to be teachers who were already positive about exploring how technology can enhance and inform pedagogy. Clearly, more teachers 
would need to be involved in further evaluation and testing of The Chase in order to establish a stronger basis for future use.

\section{Conclusions}

This pilot study establishes that The Chase digital game facilitated Italian and English elementary-aged children's co-operative responses after only a short period of game-play. In the context of this specific game where those co-operative moves were defined as prosocial, this demonstrates the positive power that digital games can have on children's immediate behaviours. There are limitations to this overall conclusion of course, not least the fact that this study was carried out over a small number of sessions and with a relatively small number of children. The very positive usability feedback from children and teachers could have been influenced by social desirability, and the allocation of students to groups by their teachers will have undoubtedly influenced the group dynamics that we captured. Moreover, given that the Italian and English school contexts are very different from each other, there could will be wider cultural as well as school-specific factors that would have influenced responses [2]. These factors are beyond the scope of this pilot study but are important considerations for future studies.

A bigger challenge for the next steps of this research is to examine whether and howlonger periods of playing prosocial digital games influences children's prosocial behaviours more widely. Indeed, this possibility was explored much more fully in a larger scale evaluation of a range of prosocial games involving 374 children in four different countries (UK, Italy, Greece, and Spain), with some positive, though highly variable, indicators for prosocial behaviours based on teacher and peer feedback (see [47] for more details). This larger-scale study certainly highlighted the variability that can arise in relation to the specific context and practicalities of particular schools, thereby serving as a helpful reminder about the importance of implementing and interpreting technology evaluation activities within their real contexts of use [2]. 
In line with the recommendations of [2], future studies could also explore in more detail the characteristics of participating children in terms of ethnicity, gender, developmental needs and socioeconomic status in order to more fully understand whether different children may gain more or less benefit from targeting prosocial skills via digital prosocial games. It was not possible to examine these factors given the small scale of the current study but such characteristics are clearly important for developing a deeper and more nuanced picture of what a fully inclusive approach might achieve in practice.

Our graphical social network analysis of a subset of the children's interactions with each other during game-play provides a novel layer of additional information about children's behaviours, revealing more of the real-world complexity of children's responses, not confined to button presses or what happens on-screen. Slovak and colleagues [48; n.p.n.] caution that a '.. reliance on in-game logs highlights the emphasis on actions and outcomes.. rather than either the emotions or motivations behind the behaviours leading to the outcomes'. Hence, it was important to try to move beyond the game logs to get more of an understanding about how children behaved towards each other during the course of the game. The visual illustration of children's dynamic interactions with each other around the game provides interesting insights into behaviours and a promising methodological foundation for enabling meaningful feedback on prosocial interactions for teachers and researchers during individual sessions and over time. There is clearly a great deal of untapped potential for this kind of analysis and so it will be valuable to continue to explore what is possible and what can be revealed. For example, to inform and influence teaching and learning practices it would be much more powerful if such a graphical display could be generated in real time during use. This could be particularly useful if moderation of children's behaviours by teachers becomes necessary (cf. [48]). However, it does not tell us about the children's emotions or motivations behind their behaviours and so there would need to be further triangulation from data of verbal interactions while playing the game as well as some post-hoc reflection on interactions. This remains a fruitful area of investigation for future research. 
Crucially, children and teachers accepted the game as an enjoyable and valid tool for supporting learning in the classroom context. With the extent of teachers' scepticism of the value of educational technologies still relatively high [e.g. 49], demonstrating such acceptability is noteworthy, even with a small sample. We did not seek parental views in this pilot study, however, and this is important for establishing wider acceptability, including for using the games at home and bridging between home and school [e.g. 50]. This is another area where more research is needed in order to be confident about where and how The Chase could be used to support children's prosocial skills and development. 


\section{Acknowledgements}

This research was funded by the ProsocialLearn project under the European Commission grant H2020-ICT-2014-1/ 644204. The authors acknowledge the support of other members of the ProsocialLearn consortium. We are very grateful to the children and teachers who participated in Italy and the UK. We also thank Christian Bokhove for very helpful guidance and feedback on the social network analysis, and Sarah Marshall for assistance with the interrater reliability check. 


\section{References}

[1] Public Health England (2015). Improving young people’s health and wellbeing: a framework for public health. PHE publications gateway number: 2014687. Available at: https:// www.gov.uk/ government/ publications/improving-young-peoples-health-andwellbeing-a-framework-for-public-health [last accessed 16th November 2017].

[2] Durlak, J . A., Weissberg, R. P., Dymnicki, A. B., Taylor, R. D., \& Schellinger, K. B. (2011). The impact of enhancing students' social and emotional learning: A meta-analysis of schoolbased universal interventions. Child Development, 82(1), 405-432.

[3] Padilla-Walker, L. M. (2016). Moral development during emerging adulthood. Chapter in J .J . Arnett (Ed.) The Oxford Handbook of Emerging Adulthood. Oxford, UK: Oxford University Press, pp. 449-461.

[4] Caprara, G. V., Kanacri, B. P. L., Gerbino, M., Zuffianò, A., Alessandri, G., Vecchio, G., ... \& Bridglall, B. (2014). Positive effects of promoting prosocial behavior in early adolescence: Evidence from a school-based intervention. International J ournal of Behavioral Development, 38(4), 386-396.

[5] Flook, L., Repetti, R. L., \&Ullman, J . B. (2005). Classroom social experiences as predictors of academic performance. Developmental Psychology, 41(2), 319-327.

[6] Banerjee, R., McLaughlin, C., Cotney, J ., Roberts, L., \& Peereboom, C. (2016) Promoting emotional health, well-being and resilience in Primary schools. Public Policy Institute for Wales. Available at: http:/ / ppiw.org.uk/ files/2016/ 02/ PPIW-Report-PromotingEmotional-Health-Well-being-and-Resilience-in-Primary-Schools-Final.pdf [last accessed $21^{\text {st }}$ April 2017].

[7] Wells, J ., Barlow, J ., \& Stewart-Brown, S. (2003). A systematic review of universal approaches to mental health promotion in schools. Health Education, 103(4), 197-220. 
[8] Bowman-Perrott, L., Burke, M. D., Zaini, S., Zhang, N., \&Vannest, K. (2016). Promoting positive behavior using the Good Behavior Game: A meta-analysis of single-case research. J ournal of Positive Behavior Interventions, 18(3), 180-190.

[9] Coombes, L., Chan, G., Allen, D., \&Foxcroft, D. R. (2016). Mixed-methods Evaluation of the Good Behaviour Game in English Primary Schools. J ournal of Community \&Applied Social Psychology, 26(5), 369-387

[10] Liu, S., Yuen, M., \& Rao, N. (2015). Outcomes for Young Children's Social Status from Playing Group Games: Experiences from a Primary School in Hong Kong. J ournal of Psychologists and Counsellors in Schools, 25(02), 217-244.

[11] Nolan, J . D., Houlihan, D., Wanzek, M., \&J enson, W. R. (2014). The Good Behavior Game: A classroom-behavior intervention effective across cultures. School Psychology International, 35(2), 191-205.

[12] Clark, D. B., Tanner-Smith, E. E., \& Killingsworth, S. S. (2016). Digital games, design, and learning: A systematic review and meta-analysis. Review of Educational Research, 86(1), 79122.

[13] Connolly, T. M., Boyle, E. A., MacArthur, E., Hainey, T., \&Boyle, J . M. (2012). A systematic literature review of empirical evidence on computer games and serious games. Computers \& Education, 59(2), 661-686.

[14] Boyle, E. A., Hainey, T., Connolly, T. M., Gray, G., Earp, J., Ott, M., Lim, T., Ninaus, M., Ribeiro, C. \& Pereira, J . (2016). An update to the systematic literature review of empirical evidence of the impacts and outcomes of computer games and serious games. Computers \& Education, 94, 178-192.

[15] Granic, I., Lobel, A., \& Engels, R. C. (2014). The benefits of playing video games. American Psychologist, 69(1), 66-78. 
[16] Stewart, J ., Bleumers, L., Van Looy, J., Mariën, I., All, A., Schurmans, D., ... \& Misuraca, G. (2013). The potential of digital games for empowerment and social inclusion of groups at risk of social and economic exclusion: evidence and opportunity for policy. J oint Research Centre, European Commission. Available at: http:/ / ftp.jrc.es/ EURdoc/ J RC78777.pdf [last accessed $16^{\text {th }}$ November 2017].

[17] Harrington, B., \&O’Connell, M. (2016). Video games as virtual teachers: Prosocial video game use by children and adolescents from different socioeconomic groups is associated with increased empathy and prosocial behaviour. Computers in Human Behavior, 63, 650658.

[18] Greitemeyer, T., \& Mügge, D. O. (2014). Video games do affect social outcomes a metaanalytic review of the effects of violent and prosocial video game play. Personality and Social Psychology Bulletin, 40(5), 578-589.

[19] Passmore, H.A., \& Holder, M.D. (2014). Gaming for good: video games and enhancing prosocial behaviour. In: J . Graham (ed.), Video Games: Parents' Perceptions, Role of Social Media and Effects on Behavior, pp. 141- 166. Hauppauge, NY: Nova Science Publishers.

[20] Gentile, D. A., Anderson, C. A., Yukawa, S., Ihori, N., Saleem, M., Ming, L. K., ... \& Huesmann, L. R. (2009). The effects of prosocial video games on prosocial behaviors: International evidence from correlational, longitudinal, and experimental studies. Personality and Social Psychology Bulletin, 35(6), 752-763.

[21] Craig, A. B., Brown, E. R., Upright, J ., \&DeRosier, M. E. (2016). Enhancing children's social emotional functioning through virtual game-based delivery of social skills training. J ournal of Child and Family Studies, 25(3), 959-968.

[22] Vieira Jr, E. T. (2014). The relationships among girls' prosocial video gaming, perspectivetaking, sympathy, and thoughts about violence. Communication Research, 41(7), 892-912. 
[23] Podsakoff, P. M., MacKenzie, S. B., Lee, J . Y., \& Podsakoff, N. P. (2003). Common method biases in behavioral research: a critical review of the literature and recommended remedies. J ournal of Applied Psychology, 88(5), 879-903.

[24] J ones, D.E., Greenberg, M., \& Crowley, M. (2015). Early Social-Emotional Functioning and Public Health: The Relationship Between Kindergarten Social Competence and Future Wellness. American J ournal of Public Health, 105(11), 2283-2290.

[25] Fletcher-Watson, S., Petrou, A., Scott-Barrett, J ., Dicks, P., Graham, C., O’Hare, A., Pain, H. \& McConachie, H., (2016). A trial of an iPad ${ }^{\mathrm{TM}}$ intervention targeting social communication skills in children with autism. Autism, 20(7), pp.771-782.

[26] Ronimus, M., Kujala, J., Tolvanen, A., \&Lyytinen, H. (2014). Children's engagement during digital game-based learning of reading: The effects of time, rewards, and challenge. Computers \&Education, 71, 237-246.

[27] Boyle, E.A., Connolly, T.M., Hainey, T., Boyle, J .M. (2012). Engagement in digital entertainment games: A systematic review. Computers in Human Behavior 28(3), 771- 780.

[28] Crook, C. (1991). Computers in the zone of proximal development: implications for evaluation. Computers \& Education, 17(1), 81-91.

[29] Abbott, C. (2007). “e-Inclusion: learning difficulties and digital technologies”. Bristol: Futurelab. https:// www.nfer.ac.uk/ publications/ FUTL66 [last accessed 16 ${ }^{\text {th }}$ November 2017].

[30] Vuillier, L., Cook, C., Star, K., Dimaraki, E., Cobello, S., Boniface, M., \&Parsons, S. (2016). D2.12nd User requirements for gamification of prosocial learning. Cambridge, GB: PROSOCIALLEARN: UCAM. Available from: https:// eprints.soton.ac.uk/404112/ [last accessed $16^{\text {th }}$ November 2017] 
[31] McGinnis, E., \& Goldstein, A. P. (1997). Skillstreaming the elementary school child: New strategies and perspectives for teaching prosocial skills. Champaign, Illinios: Research Press.

[32] Reddy, L. A. (2012). Group play interventions for children: strategies for teaching prosocial skills. Washington, D.C.: American Psychological Association. doi: 10.1037/ 13093000

[33] Rocha, J . B., Mascarenhas, S., \&Prada, R. (2008). Game mechanics for cooperative games. In N. Zagalo \& R. Prada (Eds.) ZON Digital Games 2008 (pp. 73-80). Portgual: Instituto de Ciencias Sociais

[34] Modafferi, S., Boniface, M., Crowle, S., Star, K., \&Middleton, L. (2016, May). Creating Opportunities to Learn Social Skills at School using Digital Games. In 10th European Conference on Games Based Learning: ECGBL 2016 (p. 461). Available at https:// eprints.soton.ac.uk/ 396901/ 1/ 396901.pdf [last accessed 16th November 2017].

[35] Obrist, M., Igelsböck, J ., Beck, E., Moser, C., Riegler, S., \&Tscheligi, M. (2009). Now you need to laugh!: investigating fun in games with children, In: Proceedings of the International Conference on Advances in Computer Entertainment Technology. ACM, (pp. 81-88).

[36] Weiss, P.L., Gal, E., Zancanaro, M., Giusti, L., Cobb, S., Millen, L., Hawkins, T., Glover, T., Sanassy, D., \&Eden, S. (2011). Usability of technology supported social competence training for children on the autism spectrum, In: Virtual Rehabilitation (ICVR), 2011 International Conference on IEEE (pp. 1-8).

[37] Brooke, J . (1996). SUS: A “quick and dirty” usability scale, In: J ordan, P.W., Thomas, B., Weerdmeester, B.A., McClelland, I.L. (Eds.), Usability Evaluation in Industry (pp. 189194). Taylor \& Francis, London.

[38] De Laat, M., Lally, V., Lipponen, L., \& Simons, R. J . (2007). Investigating patterns of interaction in networked learning and computer-supported collaborative learning: A role for 
Social Network Analysis. International J ournal of Computer-Supported Collaborative Learning, 2(1), 87-103.

[39] Bokhove, C. (2016). Exploring classroom interaction with dynamic social network analysis. International J ournal of Research \& Method in Education, (in press) 1-21, doi:10.1080/1743727X.2016.1192116

[40] Hughes, J. N., Im, M. H., \&Wehrly, S. E. (2014). Effect of peer nominations of teacherstudent support at individual and classroom levels on social and academic outcomes. J ournal of School Psychology, 52, 309- 322.

[41] Hoque, M. E., Courgeon, M., Martin, J . C., Mutlu, B., \&Picard, R. W. (2013, September). Mach: My automated conversation coach. In Proceedings of the 2013 ACM international joint conference on Pervasive and ubiquitous computing (pp. 697-706). ACM.

[42] Grawemeyer, B., Mavrikis, M., Holmes, W., Gutiérrez-Santos, S., Wiedmann, M., \& Rummel, N. (2017). Affective learning: improving engagement and enhancing learning with affect-aware feedback. User Modeling and User-Adapted Interaction, 27(1), 119-158.

[43] Schneider, J., Börner, D., Van Rosmalen, P., \& Specht, M. (2015). Augmenting the senses: a review on sensor-based learning support. Sensors, 15(2), 4097-4133.

[44] Weitze, C. L. (2014). Developing Goals and Objectives for Gameplay and Learning. In K. Schrier (Ed.), Learning, Education and Games: Volume One: Curricular and Design Considerations (Vol. 1, Chapter 12, pp. 225-249). Carnegie Mellon University ETC Press.

[45] Bourgonjon, J ., De Grove, F., De Smet, C., Van Looy, J ., Soetaert, R., \&Valcke, M. (2013). Acceptance of game-based learning by secondary school teachers. Computers \& Education, 67, 21-35.

[46] Marangunić, N., \& Granić, A. (2015). Technology acceptance model: a literature review from 1986 to 2013. Universal Access in the Information Society, 14(1), 81-95. 
[47] Parsons, S. \& Karakosta, E. (2018) D7.11 - Validation Activities in Operating School Conditions. DOI: 10.13140/RG.2.2.20756.55682

[48] Slovak, P., Salen, K., Ta, S., \& Fitzpatrick. G. (2018) Mediating Conflicts in Minecraft: Empowering Learning in Online Multiplayer Games. In Proceedings of the $2018 \mathrm{CHI}$ Conference on Human Factors in Computing Systems (CHI '18). ACM, New York, NY, USA, Paper 595, 13 pages. DOI: https:// doi.org/ 10.1145/3173574.3174169

[49] Teo, T. (2015). Comparing pre-service and in-service teachers' acceptance of technology: Assessment of measurement invariance and latent mean differences. Computers \& Education, 83, 22-31.

[50] Aubrey, C., \&Dahl, S. (2014). The confidence and competence in information and communication technologies of practitioners, parents and young children in the Early Years Foundation Stage. Early years, 34(1), 94-108. 
Table 1: Number of game sessions, group sizes, and data capture mode by school

\begin{tabular}{|c|c|c|c|c|}
\hline School & $\begin{array}{l}\text { Total \# of } \\
\text { sessions }\end{array}$ & \# and size of groups & $\begin{array}{l}\text { \# groups } \\
\text { playing the } \\
\text { game twice }\end{array}$ & $\begin{array}{l}\text { Data } \\
\text { capture }\end{array}$ \\
\hline $\begin{array}{l}\text { Verona school } \\
1\end{array}$ & 12 sessions & 6 groups $\mathrm{x} 4$ children & 6 & \multirow{2}{*}{$\begin{array}{l}\text { Automatic } \\
\text { logging of } \\
\text { game } \\
\text { moves }\end{array}$} \\
\hline $\begin{array}{l}\text { Verona school } \\
2\end{array}$ & 10 sessions & 6 groups $\mathrm{x} 4$ children & 4 & \\
\hline $\begin{array}{l}\text { Southampton } \\
\text { mainstream }\end{array}$ & 8 sessions & $\begin{array}{l}3 \text { groups } x 4 \text { children; } 1 \\
\text { group x } 5 \text { children }\end{array}$ & 4 & \multirow{2}{*}{$\begin{array}{l}\text { Automatic } \\
\text { logging of } \\
\text { game } \\
\text { moves + } \\
\text { video of } \\
\text { sessions }\end{array}$} \\
\hline $\begin{array}{l}\text { Southampton } \\
\text { specialist }\end{array}$ & 6 sessions & $\begin{array}{l}3 \text { pairs of children [one } \\
\text { child participating in } \\
\text { two pairs] }\end{array}$ & 3 & \\
\hline
\end{tabular}

Table 2: automatic classification of moves as logged by the game server

\begin{tabular}{|l|l|l|l|l|}
\hline $\begin{array}{l}\text { Active } \\
\text { Player } \\
\text { Threat }\end{array}$ & $\begin{array}{l}\text { Individual } \\
\text { Action }\end{array}$ & $\begin{array}{l}\text { Classification If } \\
\text { Threat to Other } \\
\text { Player }\end{array}$ & $\begin{array}{l}\text { Classification If } \\
\text { No Threat to } \\
\text { Other player }\end{array}$ & $\begin{array}{l}\text { Individual Cost } \\
\text { of Action* }\end{array}$ \\
\hline Yes & Move Self & Neutral & Neutral & No \\
\cline { 2 - 5 } & Move Other & Neutral & Neutral & Yes \\
\hline No & Move Self & Selfish & Neutral & No \\
\cline { 2 - 5 } & Move Other & Co-operative & Neutral & Yes \\
\hline
\end{tabular}

*Individual Cost of Action' means that if the player currently moving (i.e., the 'active' player) moves others instead of herself, it will cost her something (in this case, one balloon). 
Table 3: Children's Scenario Experience Feedback Questionnaire (SEFQ) responses (Southampton group)

\begin{tabular}{|c|c|c|c|c|c|}
\hline Items/Questions & Not at all & Little & Somewhat & Much & $\begin{array}{l}\text { Very } \\
\text { much }\end{array}$ \\
\hline $\begin{array}{l}\text { 1. Did you enjoy the } \\
\text { game? }\end{array}$ & 0 & 0 & 0 & 3 & 19 \\
\hline $\begin{array}{l}\text { 2. Did you succeed in } \\
\text { the game? }\end{array}$ & 4 & 2 & 4 & 4 & 8 \\
\hline $\begin{array}{l}\text { 3. Was the game easy } \\
\text { for you? }\end{array}$ & 0 & 4 & 5 & 5 & 8 \\
\hline $\begin{array}{l}\text { 4. Would you like to } \\
\text { play the game again? }\end{array}$ & 0 & 0 & 0 & 4 & 18 \\
\hline $\begin{array}{l}\text { 5. Did you feel you } \\
\text { could control the } \\
\text { game? }\end{array}$ & 1 & 0 & 3 & 9 & 8 \\
\hline $\begin{array}{l}\text { 6. Was the game quick } \\
\text { to respond when you } \\
\text { played? }\end{array}$ & 2 & 3 & 2 & 3 & 11 \\
\hline $\begin{array}{l}\text { 7. Was the computer's } \\
\text { response clear } \\
\text { during the game? }\end{array}$ & 0 & 0 & 0 & 4 & 18 \\
\hline $\begin{array}{l}\text { 8. Did you feel that you } \\
\text { took part in the } \\
\text { game? }\end{array}$ & 0 & 0 & 1 & 3 & 18 \\
\hline $\begin{array}{l}\text { 9. How quickly did you } \\
\text { get used to playing } \\
\text { the game? }\end{array}$ & 0 & 0 & 2 & 8 & 12 \\
\hline $\begin{array}{l}\text { 10. Did you feel } \\
\text { comfortable during } \\
\text { the game? }\end{array}$ & 0 & 0 & 1 & 3 & 18 \\
\hline $\begin{array}{l}\text { 11. Did you like playing } \\
\text { the game in a group? }\end{array}$ & 0 & 0 & 1 & 1 & 20 \\
\hline $\begin{array}{l}\text { 12. Did you like the } \\
\text { moving objects and } \\
\text { sounds? }\end{array}$ & 1 & 0 & 2 & 5 & 14 \\
\hline
\end{tabular}


Figures

Captions

Figure 1: Screenshots of The Chase game at the start (left) and in play (right)

Figure 2. Overview of Verona group Session 1 and Session 2 selfish and co-operative moves

Figure 3. Overview of Southampton group Session 1 and Session 2 selfish and co-operative moves

Figure 4. Total number of interactions per child and session (Southampton mainstream group)

Figure 5. Average number of interactions per group and session (Southampton mainstream group)

Figure 6. Social Network graphs per mainstream group and session 

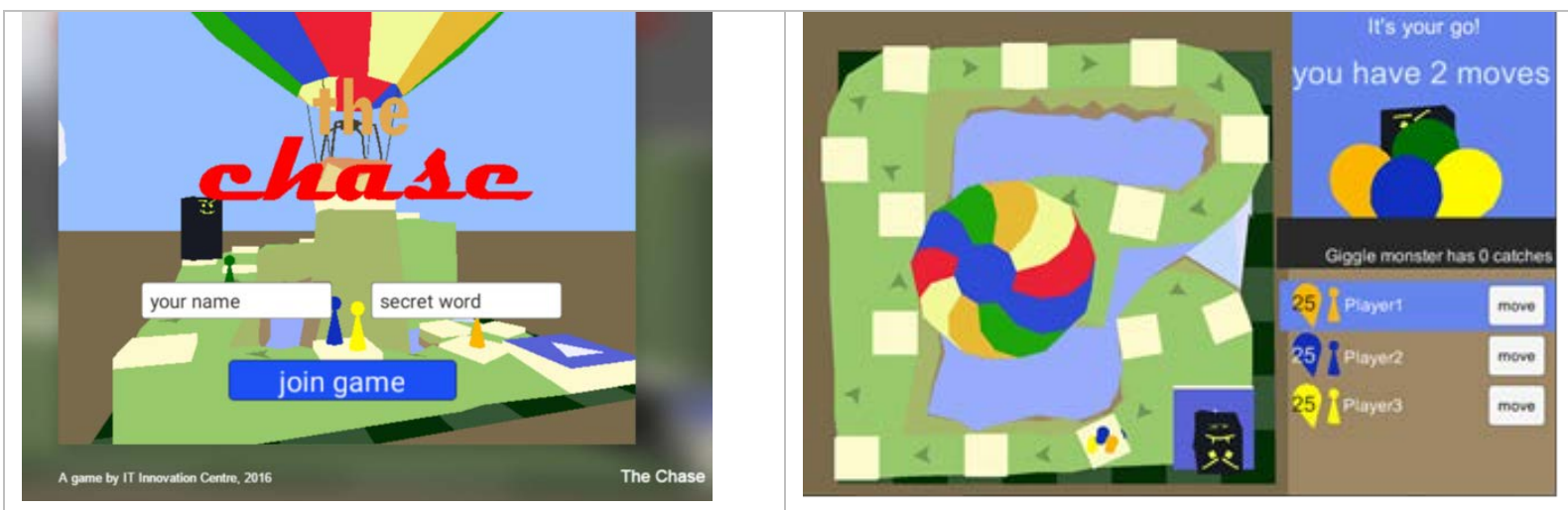

Figure 1

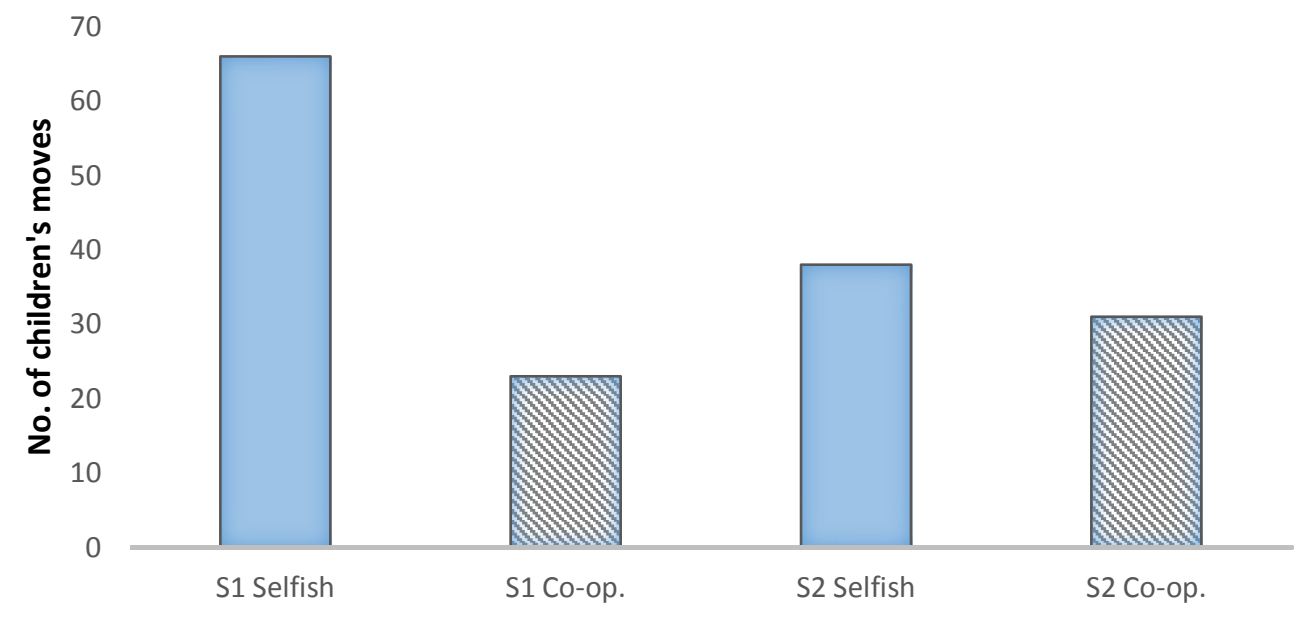

Figure 2 


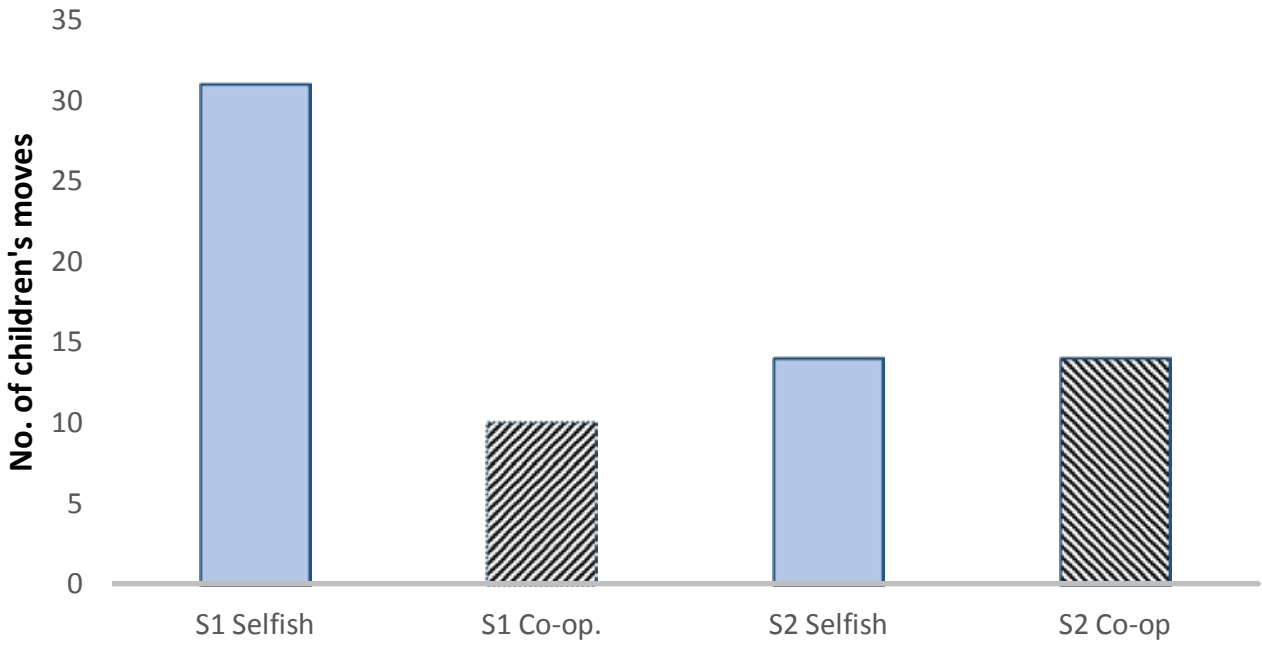

Figure 3

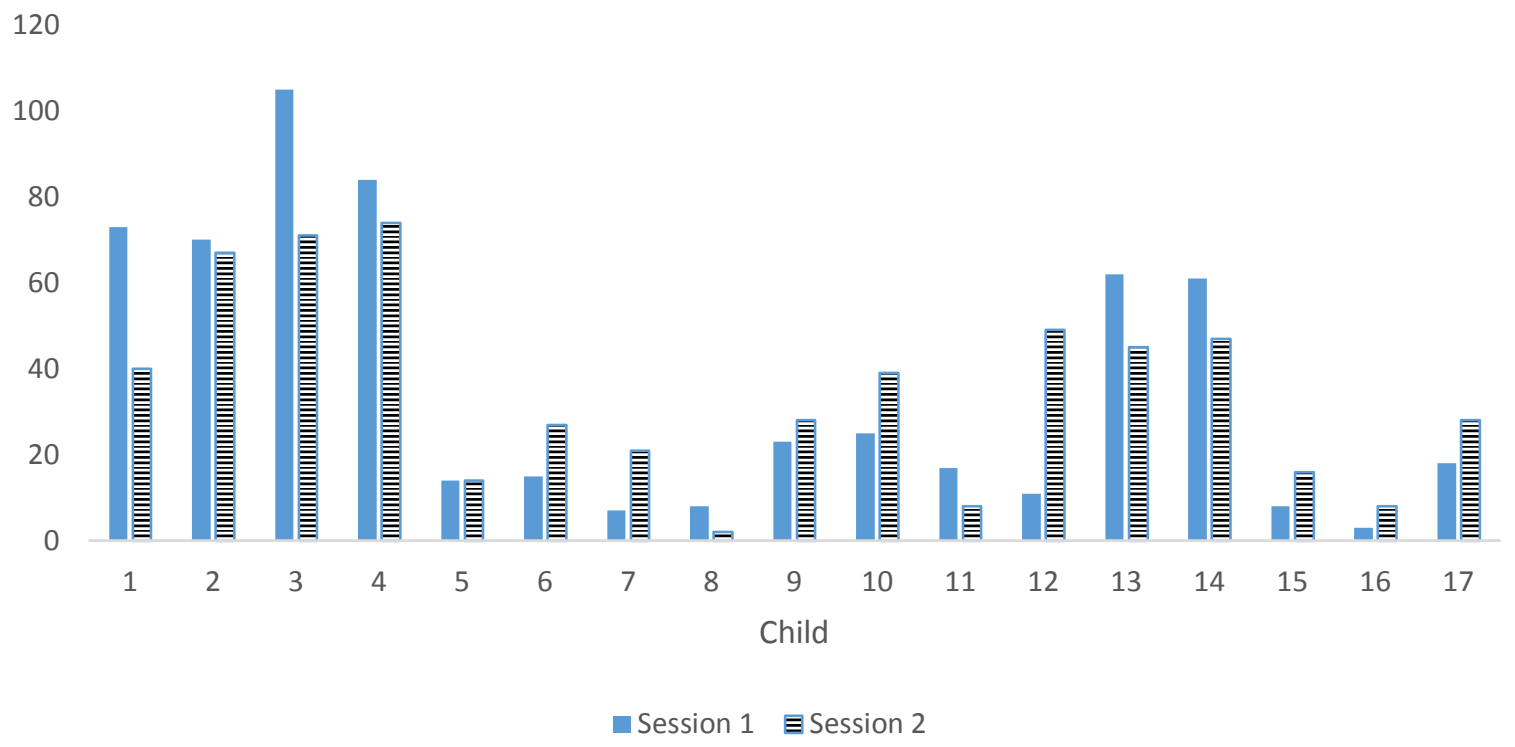

Figure 4 


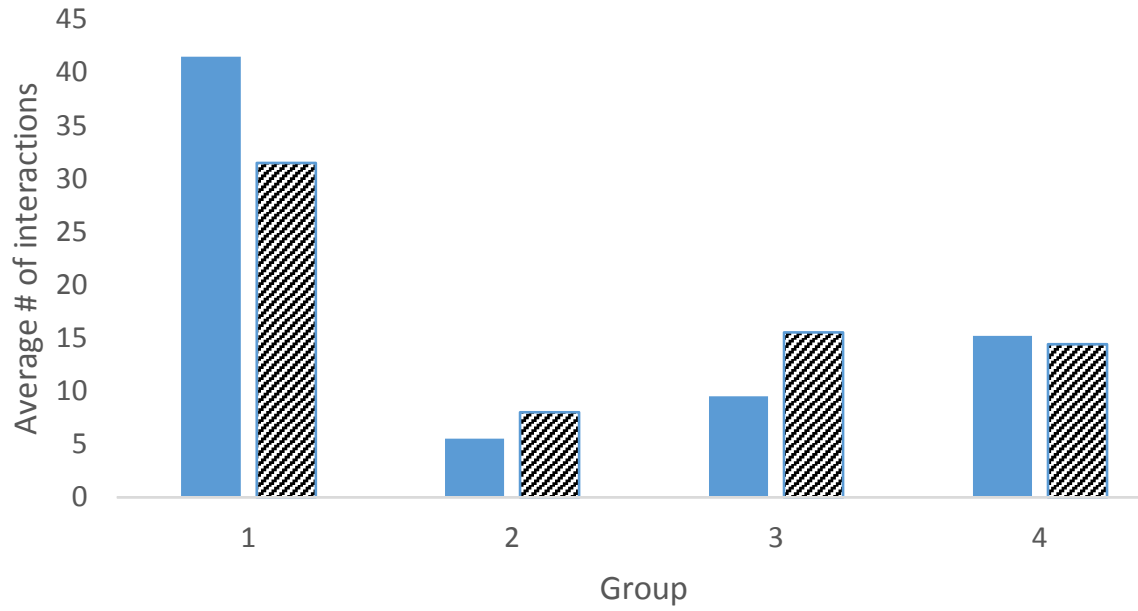

- Session 1 Z Session 2

Figure 5 
Grp

1

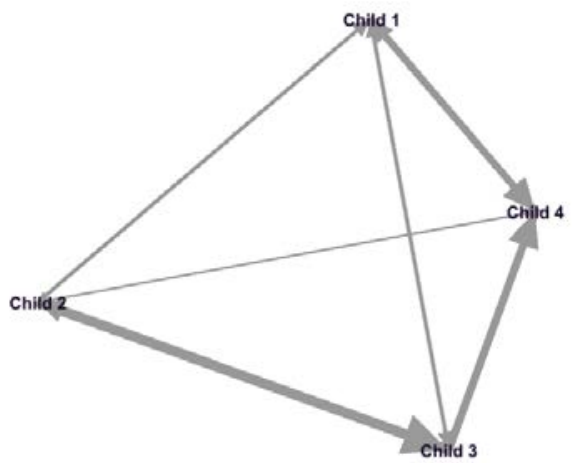

2

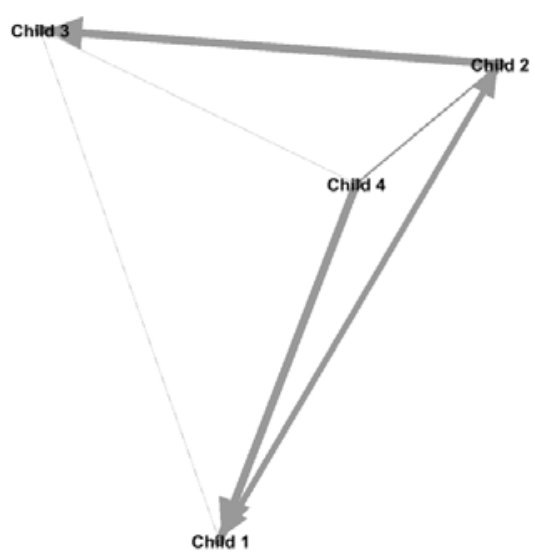

3

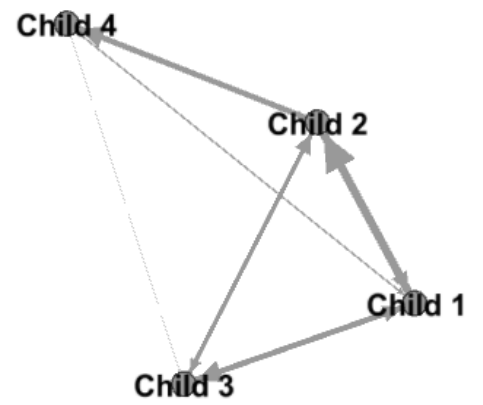

4

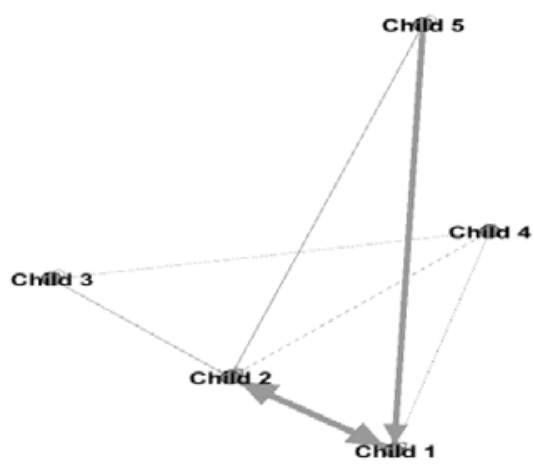

Session 2
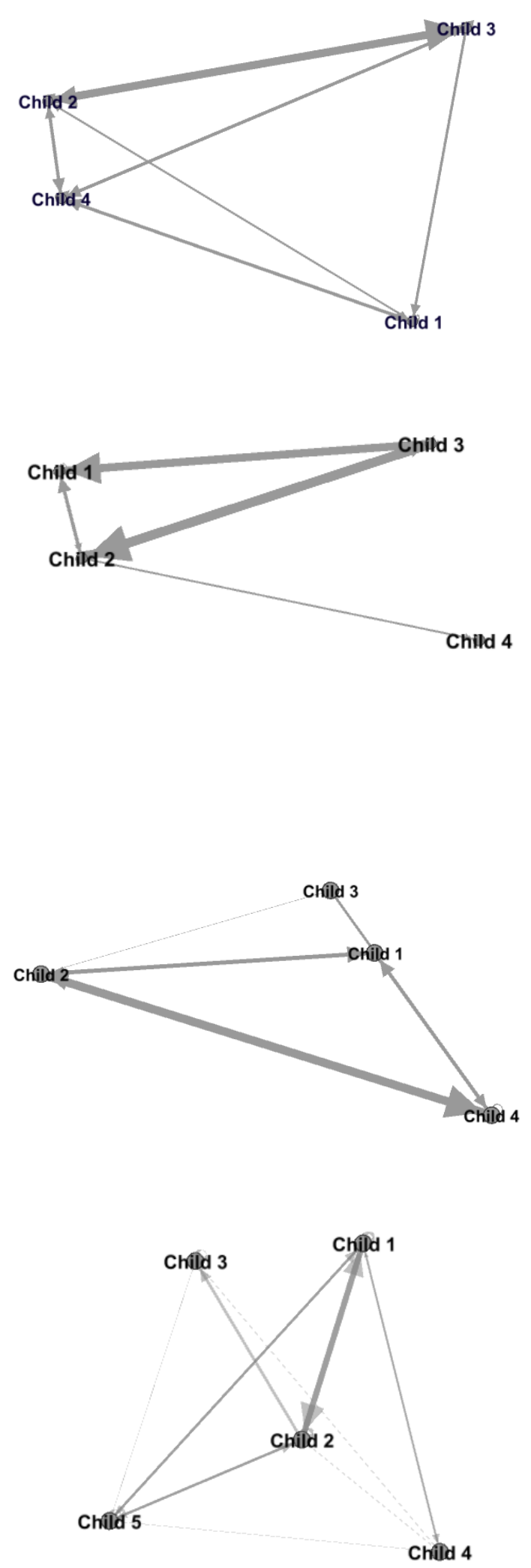

Figure 6 